\title{
A mobile telephone-based interactive self- care system improves asthma control
}

\author{
W-T. Liu*,\#, C-D. Huang*,\#, C-H. Wang*, K-Y. Lee*, S-M. Lin* and H-P. Kuo*
}

\begin{abstract}
The self-management of asthma can improve clinical outcomes. Recently, mobile telephones have been widely used as an efficient, instant personal communication tool. This study investigated whether a self-care system will achieve better asthma control through a mobile telephone-based interactive programme.

This was a prospective, controlled study in outpatient clinics. From 120 consecutive patients with moderate-to-severe persistent asthma, 89 were eventually recruited for the study, with $\mathbf{4 3}$ in the mobile telephone group (with a mobile telephone-based interactive asthma self-care system).

In the mobile telephone group, mean \pm SEM peak expiratory flow rate significantly increased at 4 (378.2 $\left.\pm 9.3 \mathrm{~L} \cdot \mathrm{min}^{-1} ; \mathrm{n}=43 ; \mathrm{p}=0.020\right), 5\left(378.2 \pm 9.2 \mathrm{~L} \cdot \mathrm{min}^{-1} ; \mathrm{n}=43 ; \mathrm{p}=0.008\right)$ and 6 months (382.7 $\left.\pm 8.6 \mathrm{~L} \cdot \mathrm{min}^{-1} ; n=43 ; p=0.001\right)$ compared to the control group. Mean $\pm \mathrm{SEM}$ forced expiratory volume in $1 \mathrm{~s}$ significantly increased at 6 months $(65.2 \pm 3.2 \%$ predicted; $n=43 ; p<0.05)$. Patients in the mobile telephone group had better quality of life after 3 months, as determined using the Short Form-12 visits than the control group. Patients in the mobile telephone group significantly increased their mean daily dose of either systemic or inhaled corticosteroids compared with the control group.

The mobile telephone-based interactive self-care system provides a convenient and practical self-monitoring and -management of asthma, and improves asthma control.
\end{abstract}

KEYWORDS: Asthma control, interactive, mobile telephone, self-care system, telemedicine

W orldwide asthma prevalence has increased very considerably in recent decades [1, 2]. The prevalence rate of adult bronchial asthma in Taipei City, Taiwan is $7.8 \%$, and its morbidity and mortality are a distinct social burden not only for patients, but also for society in general [3]. Common problems in asthma care in Taiwan and, perhaps, globally include patients seeking treatment only for acute asthma attacks, lack of concepts of long-term asthma care, poor compliance with inhaled medication, monitoring and assessment of asthma severity by symptoms and signs only, shortage of time and personnel to educate patients, and lack of objective asthma assessment [4-9].

Asthma is better controlled if patients selfmonitor their symptoms and peak flow, follow a written action plan, and regularly visit their physician [10]. However, a written action plan may be not comprehensive enough to provide guided self-management for all asthma events that happen at home. Short Message Service (SMS), a convenient, reliable, affordable and secure means of telemedicine, has been shown to improve asthma control when added to a written action plan and standard follow-up [11]. Recently, a systemic review of home telemonitoring for patients with respiratory conditions, particularly when evaluated in randomised controlled trials in asthma, showed that home telemonitoring of respiratory conditions results in early identification of deteriorations in patient condition and symptom control [12-17]. In Taiwan, an internet-based asthma telemonitoring programme reportedly increased self-management skills and improved asthma outcomes, and appeared to be an effective technology for care that is well accepted by asthmatic children and their caregivers [13]. However, telephone communication is time-consuming and staff-heavy, while internet access is not always convenient.

Mobile telephones are widely used as an efficient, instant personal communication tool, such that their function has been expanded from a simple telephone to a microcomputer. General Packer Radio Service (GPRS) is now a common function of all makes of cell phones. Through GPRS, many
AFFILIATIONS

*Dept of Thoracic Medicine, Chang Gung Memorial Hospital, Chang Gung University College of Medicine, Taipei, Taiwan, and

\#These authors contributed equally to the study.

CORRESPONDENCE

H-P. Kuo

Dept of Thoracic Medicine

Chang Gung Memorial Hospital

199 Tun Hwa N. Rd

Taipei

Taiwan

E-mail: q8828@ms11.hinet.net

Received:

Jan 042010

Accepted after revision:

June 072010

First published online:

June 182010 
interactive functions can be created to provide instant access to information. In a recent study, a mobile telephone-based system was used to provide home endurance exercise training programme, and monitor respiratory symptoms and exercise activity with good compliance and clinical outcomes in patients with moderate-to-severe chronic obstructive pulmonary disease [18]. The success of this pilot study was encouraging enough to develop an automatic, interactive communication with asthmatic patients for self-monitoring and -management using mobile telephones. In the present study, we hypothesised that patients would be aware of their daily asthma control status and obtain instant advice for corresponding management through a mobile telephone-based interactive programme, which will lead to better asthma control.

\section{MATERIALS AND METHODS}

\section{Study subjects and design}

This prospective randomised controlled study enrolled 120 patients with moderate-to-severe persistent asthma from the outpatient clinics of Chang Gung Memorial Hospital, Linkou, a tertiary teaching medical centre in northern Taiwan (fig. 1). All asthmatic subjects met the criteria for asthma as defined by the American Thoracic Society [19] on the basis of clinical symptoms and physical examination. Patients were treated according to their current severity level by the Global Initiative for Asthma (GINA) guidelines [20] and they were taught how to adjust their medication. All subjects received asthma education, self-management plan, and standard treatment. They were asked to measure and record daily peak expiratory flow rate (PEFR) and asthma symptoms on a diary.

After informed consent was obtained, the patients were randomised into two groups (mobile telephone and control groups). Patients were evaluated on their quality of life using the Short form (SF)-12® questionnaire, episodes of acute exacerbation and medications used for asthma control on their return visit, monthly for 6 months. Pulmonary function tests, including forced expiratory volume in $1 \mathrm{~s}$ (FEV1) and forced vital capacity (FVC), were performed every 3 months. Asthma symptom score, and number of unscheduled clinic visits, emergency department visits, and hospitalisations during the study period were also recorded.

All the patients recruited into the study received asthma education as part of their regular care, including verbal and printed information, as well as concepts related to asthma control. A series of instructional sheets were available with the asthma programme to help patients understand asthma, selected devices, medications and environmental control. The study was approved by the Institutional Review Board of Chang Gung Memorial Hospital Ethics Committee. Informed consent was obtained from all subjects.

\section{Mobile telephone-based interactive asthma self-care system}

The present study developed a mobile telephone-based interactive self-care software. It was created under the collaboration between the Taiwan Chest Disease Association and National Center for High-Performance Computing, Hsinchu, Taiwan. The self-care software provided an electronic diary to record patients' daily asthma symptom score (sleep quality, severity of coughing, difficulty in breathing and daily activities affected by asthma), use of relievers, peak expiratory flow rate (PEFR) and PEFR variability.

Patients were taught how to use the software, which was installed on patients' mobile telephones. They were loaned a self-care system compatible mobile telephone if they did not have a compatible one. The uploaded data were stored and automatically computed in their personal files in a secured server at the information center of the National Center for High-Performance Computing.

In the mobile telephone-based self-care system, the level of asthma control was assessed by PEFR, the need for reliever use and the daily asthmatic symptoms that were assessed using the methods in the Global Initative for Asthma (GINA) guidelines 2006. We developed a scoring system for computing

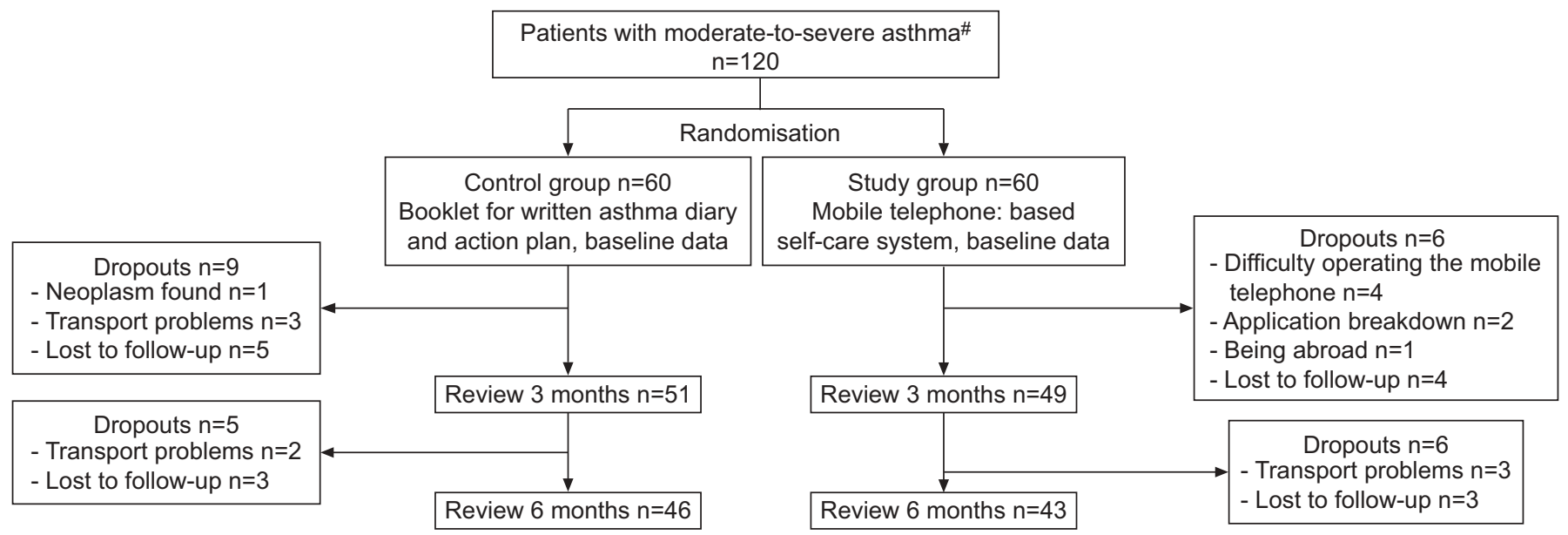

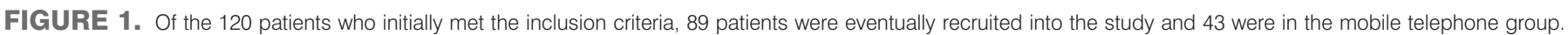

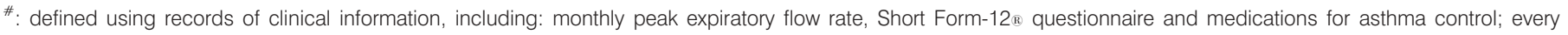

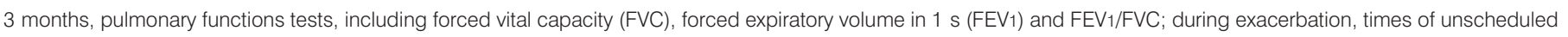
visits and hospitalisation. 


\begin{tabular}{|c|c|c|}
\hline \multicolumn{2}{|r|}{ PEFR $<80 \%$ pred (or personal best) or variability $>30 \%$} & 1 \\
\hline \multicolumn{2}{|r|}{ Need for reliever/rescue treatment: $>2$ times $\cdot$ week $^{-1}$} & 1 \\
\hline \multicolumn{3}{|c|}{ In sleep (daily asthmatic symptom score) } \\
\hline 0 & Sleeping was not interrupted by asthma & \multirow{2}{*}{0} \\
\hline 1 & Sleeping was lightly interrupted by asthma & \\
\hline 2 & Woken by asthma attack during sleep & \multirow{2}{*}{1} \\
\hline 3 & Could not fall asleep because of asthma attack & \\
\hline
\end{tabular}

Severity of coughing (daily asthmatic symptom score)

\begin{tabular}{|l|l|l|}
\hline 0 & None & 0 \\
\hline 1 & Sometimes & \\
\hline 2 & Frequent & 1 \\
\hline 3 & All day long & \\
\hline
\end{tabular}

Difficulty in breathing (daily asthmatic symptom score)

\begin{tabular}{|l|l|l|}
\hline 0 & None & 0 \\
\hline 1 & Light & \\
\hline 2 & Frequent & 1 \\
\hline 3 & Severe & \\
\hline
\end{tabular}

Daily activities affected by asthma (daily asthmatic symptom score)

\begin{tabular}{|c|l|l|}
\hline 0 & Not at all & 0 \\
\hline 1 & Unable to do more active activties & 1 \\
\hline 2 & Having difficulties performing normal daily activities & 1 \\
\hline 3 & Unable to do anything & 1 \\
\cline { 1 - 2 } $\begin{array}{l}\text { Overall asthmatic symptoms: total score of daily asthmatic } \\
\text { symptom }>6\end{array}$ & \\
\hline
\end{tabular}

\begin{tabular}{|c|l|}
\hline \multicolumn{2}{|l|}{ Levels of asthma control: } \\
\hline 0 & Controlled \\
\hline $1-3$ & Partly controlled \\
\hline$>3$ & Uncontrolled \\
\hline
\end{tabular}

Management based on asthma control

Controlled

"Your present condition is stable. The present treatment is quite proper for you; there is no need to change the dosage of drugs. You should continue to maintain this condition for at least 3 months; then consider decreasing the dosage or the number of drugs. Please return to OPD clinic on schedule..."

Partly controlled

1. If PEFR $<80 \%$ or rescue treament used: "Asthma control is not ideal although without apparent asthma symptoms. The symptoms may not precisely reflect the pulmonary function. You may increase the doses of the present anti-inflammatory agents (steroids/antileukotrienes)."

2. If with apparent asthmatic symptoms: "Please maintain the present treatment and you may try to use short acting $\beta_{2}$-agonists to relieve symptoms. If the symptoms persist, it is possible that the symptoms may not be caused by asthma (such as sinusitis, gastroesophageal reflux, upper airway dysfunction, etc). Please return to OPD clinic and discuss with your doctor and may increase anti-inflammatory agents if needed..."

Uncontrolled

"Your asthma is uncontrolled. You should increase the doses of the present anti-inflammatory agents (steroids/anti-leukotrienes), or add long acting $\beta_{2}$-agonist on the existing medications. Review the concepts of medication utility and check whether you take bronchodilators alone without anti-inflammatory agents. Return to OPD clinic and discuss with your doctor for the other reasons causing asthmatic symptoms..."

FIGURE 2. Management approach based on levels of asthma control. Symptoms were categorised according to sleep quality, severity of coughing, difficulty breathing and daily activities affected by asthma. Each question was answered on a four-point scale from $0-3$. The score system was ranged from 0-1 in each question and a simplified level of asthma control for controlled (total score 0), partly controlled (total score 1-3), and uncontrolled (total score $>3$ ) asthma was provided. The system provided the management suggestions on the cell phone. PEFR: peak expiratory flow rate; \% pred: \% predicted. OPD: outpatient department.

the result in the data centre: first, the result of PEFR was scored as 1 if it was $<80 \%$ of the patient's best value or its variability was above $30 \%$; otherwise, it was scored as 0 . Secondly, if there was a need for reliever, use the score was 1 , or otherwise 0 . Thirdly, the method to assess the daily asthmatic symptoms was modified because, in real life, these symptoms may not be described clearly by the patients themselves. We categorised the symptoms using four questions on sleep quality, severity of coughing, difficulty breathing and daily activities affected by asthma. Each question was answered on a four-point scale from 0 to 3, for the convenience of the patient. Then, the score for each question was converted to 0 if the patient choses 0 or 1 , and 1 if 2 or 3 was answered. Finally, the overall asthmatic symptoms were scored as 1 if the total answered score of the four questions was $>6$. After calculating the sum of scores from the results of PEFR value, need for reliever use, daily and overall asthmatic symptoms, the patient's asthma was recognised as controlled (total score 0 ), partly controlled (total score 1-3) or uncontrolled (total score $>3$ ) (fig. 2). After uploading the diary data, according to the level of asthma control calculated in the data centre, the patient received the assessment of their asthma status and the corresponding management advice, which were displayed immediately on the mobile telephone via GPRS. The assessment of asthma control was determined by the data uploaded within the previous 7 days. Patients in the mobile telephone group were asked to follow the management advice to adjust their antiinflammatory agents if there was high variability of PEFR, increased frequency of daytime or nighttime asthma episodes, or decreased response to bronchodilators (fig. 3). These management suggestions were based on GINA guidelines for asthma control (online supplemetary figs 1-3).

The patients were always asked to examine medication compliance, control environmental factors and emotional stress, review concomitant medications, and aggressively treat their rhinosinusitis or gastro-oesophageal reflux before adjusting their anti-inflammatory agents when they lose their asthma control. The patients and medical staff reviewed the daily, weekly and monthly data of patients' asthma symptom scores, 


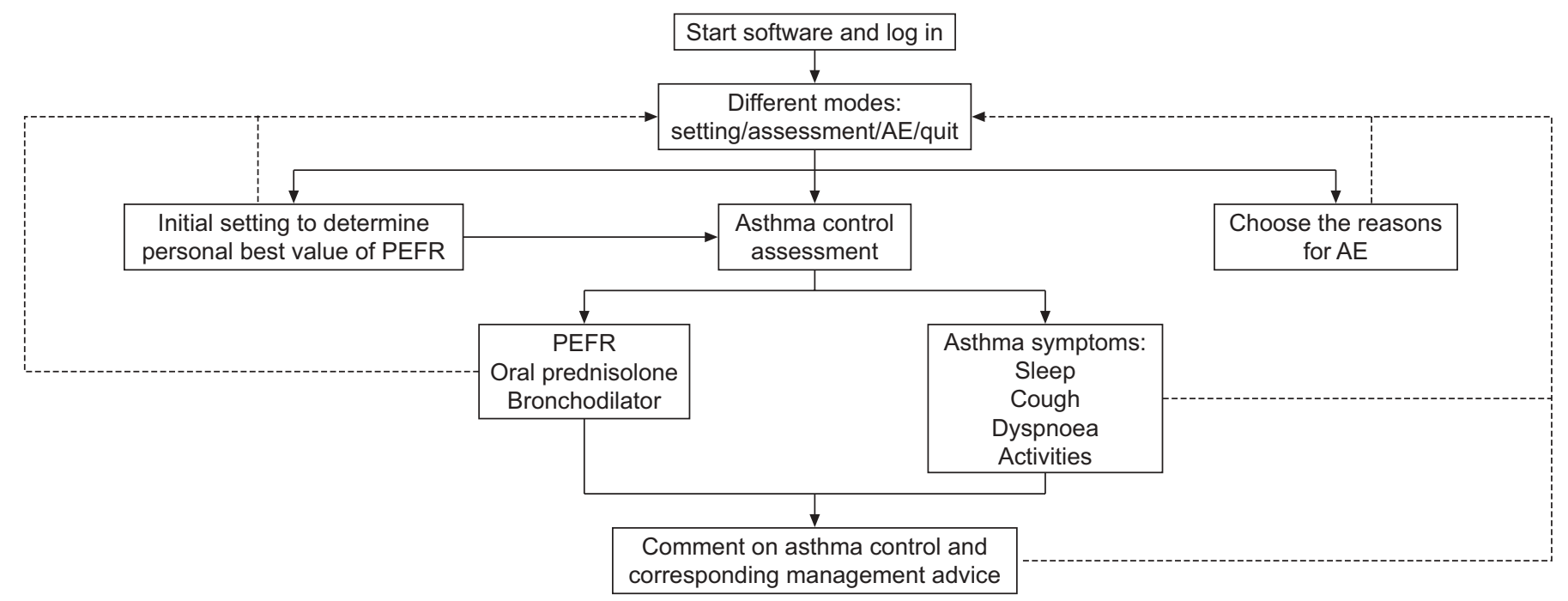

FIGURE 3. Flow chart of the mobile telephone-based interactive asthma self-care system. AE: acute exacerbation; PEFR: peak expiratory flow rate; —: "usual" pathway; ---: "backward" pathway.

PEFR, PEFR variability and use of relievers on the website. The data were given to the physicians to adjust their treatment plan when patients returned to their clinics. Additional details on the mobile telephone phone self-care system were provided at http://asthma.tcda.tw (in Chinese).

\section{Control group booklet for written asthma diary and action plan}

The control group participants were given a asthma symptom diary booklet and were asked to record their PEFR regularly, preferably daily. All patients received an individualised asthma action plan with detailed instructions for daily selfmanagement, as well as guidelines for handling exacerbations and emergencies. The action plan comprised of a three-colour warning system based on the symptoms score and PEFR values. The patients were treated according to the GINA guidelines and were taught how to adjust their medications.

\section{Data security within the mobile telephone-based system}

Data captured by the mobile telephone was held on a secure database by the National Center for High-Performance Computing. The transmission of data and its availability to the patients and to their healthcare professionals was provided in a secure manner. All subject-identifiable data was encrypted. Access to the data was logged in using personal high-security username and password. Access was limited to the clinicians managing the patients and restricted members of the research team, with the patients' permission.

\section{Statistical analysis}

Data are presented as mean \pm SEM. One-way ANOVA for was used to compare mean values of more than two study groups. A two-tailed, unpaired t-test or nonparametric Mann-Whitney test was applied to compare results between the two groups. Frequencies of contribution of factors were compared between groups by Chi-squared test. A p-value $<0.05$ was considered statistically significant.

\section{RESULTS}

\section{Compliance with mobile telephone-based interactive self-} care system

During the study period, 120 patients initially met the inclusion criteria (fig. 1). Of patients in the mobile telephone group, $49(81.7 \%)$ patients and $43(71.7 \%)$ patients were still adherent to the interactive self-care system and sent data to the website by GPRS for 3 and 6 months, respectively. 51 (85\%) patients and $46(76.7 \%)$ patients in the control group were still adherent to the written asthma diary booklet and action plan for 3 and 6 months, respectively. In the mobile telephone group, six $(35.3 \%)$ of the patients who withdrew from the study did so due to problems with the mobile telephone itself: four patients has difficulty operating the telephone and two patients had application breakdowns. One (5.9\%) out of 17 patients who withdrew left the country during the first 3 months of this study and another three (17.6\%) patients withdrew due to transport problems. In the control group, one (7.1\%) of the 14 patients who withdrew from the study was diagnosed with a neoplasm and five $(35.7 \%)$ patients withdrew due to transport problems during the study period. There were also seven (41.2\%) out of 17 patients and eight $(57.1 \%)$ out of 14 patients lost to follow-up in the mobile telephone phone and control groups, respectively. Eventually, 89 patients were enrolled in the study, 43 of whom were in the mobile telephone group.

\section{Baseline characteristics of the study subjects}

The characteristics of the study subjects were shown in table 1. There was no significant difference between the two groups in terms of age, sex, body mass index, asthma severity or baseline pulmonary function. There were no significant differences in either maintenance medications or baseline SF-12 $₫$ Scores.

\section{Pulmonary function}

In the mobile telephone group, mean \pm SEM PEFR increased significantly at $4\left(378.2 \pm 9.3 \mathrm{~L} \cdot \mathrm{min}^{-1} ; \mathrm{n}=43 ; \mathrm{p}=0.020\right), 5(378.2 \pm$ $\left.9.2 \mathrm{~L} \cdot \mathrm{min}^{-1} ; \mathrm{n}=43 ; \mathrm{p}=0.008\right)$ and 6 months $\left(382.7 \pm 8.6 \mathrm{~L} \cdot \mathrm{min}^{-1}\right.$; 


\begin{tabular}{|c|c|c|c|}
\hline & Control & $\begin{array}{l}\text { Mobile } \\
\text { telephone }\end{array}$ & p-value \\
\hline Subjects & 46 & 43 & \\
\hline Age yrs & $54.0 \pm 2.4$ & $50.4 \pm 1.9$ & 0.247 \\
\hline Males & $22(47.8)$ & $22(51.2)$ & 0.756 \\
\hline$B M I \mathbf{k g} \cdot \mathrm{m}^{-2}$ & $24.3 \pm 0.5$ & $24.0 \pm 0.5$ & 0.672 \\
\hline SF-12 PCS & $43.2 \pm 1.4$ & $41.6 \pm 1.5$ & 0.460 \\
\hline SF-12 MCS & $48.6 \pm 1.2$ & $48.6 \pm 1.1$ & 0.886 \\
\hline FVC L & $2.01 \pm 0.11$ & $2.18 \pm 0.11$ & 0.138 \\
\hline FEV 1 L & $1.57 \pm 0.09$ & $1.40 \pm 0.09$ & 0.083 \\
\hline FEV $1 \%$ pred & $58.2 \pm 3.1$ & $57.9 \pm 3.0$ & 0.825 \\
\hline $\mathrm{FEV}_{1 / \mathrm{FVC}} \%$ & $68.4 \pm 1.8$ & $70.5 \pm 1.7$ & 0.297 \\
\hline PEFR L. $\min ^{-1}$ & $350.1 \pm 7.8$ & $352.2 \pm 10.3$ & 0.997 \\
\hline Inhaled corticosteroids ${ }^{\#} \mu \mathrm{g}$ & $619.6 \pm 33.6$ & $604.7 \pm 41.0$ & 0.546 \\
\hline Systemic corticosteroids $\mathrm{mg}$ & $1.3 \pm 0.4$ & $1.2 \pm 0.4$ & 0.886 \\
\hline Systemic corticosteroids & $9(19.6)$ & $8(18.6)$ & 0.908 \\
\hline Antileukotrienes $^{+}$ & $14(30.4)$ & $19(44.2)$ & 0.180 \\
\hline
\end{tabular}

Data are presented as $n$, mean \pm SEM or $n(\%)$, unless otherwise stated. BMI: body mass index; SF: Short Form; PCS: physical component score; MCS: mental component score; FVC: forced vital capacity; FEV1: forced expiratory volume in $1 \mathrm{~s}$; $\%$ pred: \% predicted; PEFR: peak expiratory flow rate. \#: fluticasone propionate or equivalent. ": prednisolone. ${ }^{+}$: montelukast.

$\mathrm{n}=43 ; \mathrm{p}=0.001)$ compared with the control group. The morning PEFR of patients in the mobile telephone group increased from baseline $\left(352.2 \pm 10.3 \mathrm{~L} \cdot \mathrm{min}^{-1}\right)$ to $376.3 \pm 9.2 \mathrm{~L} \cdot \mathrm{min}^{-1}$ at 3 $(\mathrm{n}=43 ; \mathrm{p}=0.0017), 378.2 \pm 9.3 \mathrm{~L} \cdot \mathrm{min}^{-1}$ at $4(\mathrm{n}=43 ; \mathrm{p}=0.002)$, $378.2 \pm 9.2 \mathrm{~L} \cdot \mathrm{min}^{-1}$ at $5(\mathrm{n}=43 ; \mathrm{p}=0.005)$ and $382.7 \pm 8.6 \mathrm{~L} \cdot \mathrm{min}^{-1}$ at 6 months $(n=43 ; p=0.002)$. There was no significant change during the study period in the mean PEFR of the control group (table 2).

\begin{tabular}{|c|c|c|c|c|}
\hline \multirow[t]{3}{*}{ TABLE : } & \multicolumn{4}{|c|}{ Pulmonary function } \\
\hline & \multicolumn{2}{|c|}{ PEFR L. $\min ^{-1}$} & \multicolumn{2}{|c|}{ FEV $1 \%$ pred } \\
\hline & Control & $\begin{array}{l}\text { Mobile } \\
\text { telephone }\end{array}$ & Control & $\begin{array}{l}\text { Mobile } \\
\text { telephone }\end{array}$ \\
\hline Subjects & 46 & 43 & 46 & 43 \\
\hline Baseline & $350.1 \pm 7.8$ & $352.2 \pm 10.3$ & $58.2 \pm 3.1$ & $57.9 \pm 3.0$ \\
\hline 1 month & $348.9 \pm 7.2$ & $357.6 \pm 10.0$ & & \\
\hline 2 months & $351.1 \pm 7.2$ & $364.3 \pm 9.7$ & & \\
\hline 3 months & $353.9 \pm 7.9$ & $376.3 \pm 9.2^{*}$ & $60.0 \pm 3.3$ & $63.7 \pm 2.9^{\star \star}$ \\
\hline 4 months & $350.4 \pm 7.4$ & $378.2 \pm 9.3^{\star, \#}$ & & \\
\hline 5 months & $346.8 \pm 7.2$ & $378.2 \pm 9.2^{\star, \#}$ & & \\
\hline 6 months & $343.5 \pm 7.7$ & $382.7 \pm 8.6^{*, \#}$ & $56.5 \pm 2.8$ & $65.2 \pm 3.2^{\star * . \#}$ \\
\hline
\end{tabular}

Data are presented as $n$ or mean \pm SEM. PEFR: peak expiratory flow rate; FEV 1 : forced expiratory volume in $1 \mathrm{~s} ; \%$ pred: \% predicted. *: $p<0.05$ compared with baseline; **: $p<0.01$ compared with baseline; ${ }^{*}: p<0.05$ for control group versus mobile telephone group.
In the mobile telephone group, the FEV1 \% predicted significantly increased at 6 months $(65.2 \pm 3.2 \%$; $n=43$; $\mathrm{p}<0.05)$ compared to the control group and baseline. FEV1 \% pred also significantly increased from baseline $(57.9 \pm 3.0 \%)$ in the mobile telephone group to $63.7 \pm 2.9 \%$ at 3 months $(n=43$; $\mathrm{p}=0.005)$ and $65.2 \pm 3.2 \%$ at 6 months $(\mathrm{n}=43 ; \mathrm{p}<0.001)$ (table 2). In contrast, there was no significant change in predicted FEV1 values during the study period in the control group (table 2).

\section{Quality of life}

Patients in the mobile phone group improved their quality of life (QoL), with a significant increase in SF-12 ${ }_{\circledR}$ physical component score from the baseline value $(41.6 \pm 1.5)$ to $45.2 \pm 1.3(n=43 ; p=0.045)$ after 2 months, and then throughout the rest of the study period (table 3). Patients in the mobile telephone group had better QoL in terms of SF-12 ${ }$ PCS after 3 months of the study when compared with patients in the control group (table 3).

There was no significant change of the SF-12 ${ }_{\circledR}$ mental component score (MCS) in the mobile telephone group throughout the study period (table 3). However, the SF-12 MCS in the control group decreased significantly at $4(43.6 \pm 1.4 ; \mathrm{n}=46 ; \mathrm{p}<0.001), 5(43.6 \pm 1.5 ; \mathrm{n}=46 ; \mathrm{p}=0.004)$ and 6 months $(44.4 \pm 1.4 ; n=46: p=0.008)$ from the baseline value $(48.6 \pm 1.2)$ (table 3$)$.

\section{Medications used for asthma control}

Compared to baseline medications, patients in the mobile telephone group significantly increased their mean daily dosage of either inhaled or systemic corticosteroids during the study period. There was no significant change in the dosage of steroids in the control group (table 4).

Patients in the mobile telephone group used more antileukotrienes to control their asthma than those in the control group. The percentage of patients treated with antileukotrienes in the mobile telephone group was significantly higher than that in

\begin{tabular}{|c|c|c|c|c|}
\hline & \multicolumn{2}{|c|}{ SF-12 PCS } & \multicolumn{2}{|c|}{ SF-12 MCS } \\
\hline & Control & $\begin{array}{l}\text { Mobile } \\
\text { telephone }\end{array}$ & Control & $\begin{array}{c}\text { Mobile } \\
\text { telephone }\end{array}$ \\
\hline Subjects & 46 & 43 & 46 & 43 \\
\hline Baseline & $43.2 \pm 1.4$ & $41.6 \pm 1.5$ & $48.6 \pm 1.2$ & $48.6 \pm 1.1$ \\
\hline 1 month & $42.7 \pm 1.4$ & $42.6 \pm 1.6$ & $48.2 \pm 1.2$ & $50.1 \pm 1.0$ \\
\hline 2 months & $41.7 \pm 1.5$ & $45.2 \pm 1.3^{\star}$ & $48.0 \pm 1.1$ & $50.0 \pm 1.3$ \\
\hline 3 months & $41.3 \pm 1.4$ & $47.5 \pm 1.2^{\star, \star \star}$ & $47.7 \pm 1.4$ & $50.7 \pm 1.1$ \\
\hline 4 months & $38.9 \pm 1.4^{*}$ & $45.6 \pm 1.3^{\star \star \star \star}$ & $43.6 \pm 1.4^{\star \star \star \star}$ & $50.9 \pm 1.0$ \\
\hline 5 months & $38.6 \pm 1.5^{\star}$ & $46.4 \pm 1.2^{\star \star \star \star *}$ & $43.6 \pm 1.5^{\star \star \star \star}$ & $49.3 \pm 1.1$ \\
\hline 6 months & $40.0 \pm 1.5$ & $45.5 \pm 1.4^{\star, \star \star}$ & $44.4 \pm 1.4^{\star \star \star \star}$ & $50.4 \pm 1.1$ \\
\hline
\end{tabular}

Data are presented as $n$ or mean \pm SEM. SF: Short Form; PCS: physical component score; MCS: mental component score. ${ }^{*}$ : $p<0.05$ compared with baseline; ${ }^{*}: \mathrm{p}<0.01$ for control group versus mobile telephone group. 
TABLE 4 Medications used for asthma control

\begin{tabular}{|c|c|c|c|c|c|c|}
\hline & Control & Mobile telephone & Control & Mobile telephone & Control & Mobile telephone \\
\hline Subjects & 46 & 43 & 46 & 43 & 46 & 43 \\
\hline Baseline & $620 \pm 34$ & $605 \pm 41$ & $1.30 \pm 0.42$ & $1.16 \pm 0.40$ & $14(30.4)$ & $19(44.2)$ \\
\hline 1 month & $625 \pm 33$ & $651 \pm 41^{*}$ & $1.20 \pm 0.42$ & $1.51 \pm 0.49$ & $15(32.6)$ & $21(38.8)$ \\
\hline 4 months & $609 \pm 40$ & $663 \pm 38^{*}$ & $1.30 \pm 0.39$ & $2.21 \pm 0.58^{*}$ & $16(34.8)$ & $19(44.2)$ \\
\hline 5 months & $598 \pm 39$ & $686 \pm 39^{*}$ & $1.20 \pm 0.35$ & $2.27 \pm 0.58^{*}$ & $16(34.8)$ & $19(44.2)$ \\
\hline 6 months & $630 \pm 39$ & $709 \pm 32^{*}$ & $1.25 \pm 0.35$ & $2.38 \pm 0.56^{*}$ & $16(34.8)$ & $17(39.5)$ \\
\hline
\end{tabular}

Data are presented as $n$, mean \pm SEM or $n(\%)$. ICS: inhaled corticosteroids. *: $p<0.05$ compared with baseline; ${ }^{*}: p<0.05$ for control group versus mobile telephone group

the control group at 2 months (60.5 versus $34.8 \%$, respectively; $\mathrm{p}=0.015)($ table 4).

\section{Clinical outcomes after 6 months of follow-up}

Patients in the mobile telephone group had fewer episodes of exacerbation and unscheduled visits than those in the control group (table 5).

\section{DISCUSSION}

The results of the present study demonstrate that a mobile telephone-based interactive self-care system may offer better self-management of asthma than a written action plan, in terms of improving pulmonary function (FEV1 and PEFR) and QoL, and decreasing episodes of exacerbation and unscheduled visits. The increased dosage of corticosteroids and antileukotrienes used for asthma control in the mobile telephone group suggests increased dosage of anti-inflammatory agents for the fluctuating course of asthma and accounts for better asthma control.

\section{TABLE 5 Clinical outcomes at 6 months}

\begin{tabular}{lcc} 
& Control & $\begin{array}{c}\text { Mobile } \\
\text { telephone }\end{array}$ \\
\hline $\begin{array}{l}\text { Subjects } \\
\text { Unscheduled visits to the emergency dept }\end{array}$ & 46 & 43 \\
$\quad$ Patients & $9(20)^{*}$ & $2(4.4)$ \\
$\quad$ Visits & 12 & 2 \\
$\quad$ Visits per patient & 0.267 & 0.044 \\
Hospitalisation & $1(2.2)$ & 0 \\
$\quad$ Patients & 1 & 0 \\
$\quad$ Visits & 0.022 & 0 \\
$\quad$ Visits per patient & 0 & 0 \\
Respiratory failure & 0 & 0 \\
Mortality & & \\
\hline $\begin{array}{l}\text { Data are presented as } \mathrm{n} \text { or } \mathrm{n}(\%) .{ }^{*}: \mathrm{p}<0.05 \text { compared with corresponding } \\
\text { mobile telephone group. }\end{array}$ &
\end{tabular}

Based on the National Heart, Lung and Blood Institute (Bethesda, MD, USA) treatment guidelines, a patient-centred, comprehensive asthma health management programme has been shown to improve processes of care and outcomes over a 2-yr period [21]. Many studies have also demonstrated that long-term monitoring of asthma severity and use of action plans for self-management can reduce asthma exacerbations, optimise drug therapy and decrease the cost of asthma management [10]. In the present study, the daily PEFR and symptom scores were well monitored in the mobile telephone group and patients received a corresponding recommendation of management on their mobile telephone for their change in PEFR and symptom score. Therefore, early medical intervention may be implemented to prevent deterioration.

Persistent asthma symptoms, and delayed and insufficient anti-inflammatory treatment are associated with deterioration of lung function in asthma, reduced bronchodilator response and enhanced exacerbation rates [22-24]. Anti-inflammatory treatment was mostly adjusted during the subsequent clinic visit according to the level of asthma control. Change in asthma control may not be significant enough to draw the patients' attention if patients do not frequently monitor and assess their asthma severity, which may result in unscheduled clinic visits if conditions become more severe.

In this study, the level of asthma control in the mobile telephone group was assessed regularly and patients were advised to increase the use of anti-inflammatory treatment when they lost asthma control. Thus, patients were able to take sufficient anti-inflammatory treatment without delay. This interactive care system also provided information for patients to find out the causes of their loss of asthma control and avoid unnecessary increases in anti-inflammatory treatment. In contrast, the written action plan in the control group may not have been comprehensive enough for patients to adjust the use of anti-inflammatory treatment, leading to increased asthma exacerbation episodes, unscheduled visits and decline in pulmonary function.

Change in overall asthma QoL score correlates significantly with FEV1, forced expiratory flow at $25-75 \%$ of FVC and morning PEFR [25]. A cohort study showed that both the PCS 
score and the asthma QoL questionnaire score are associated with subsequent asthma-related emergency department utilisation, suggesting that better QoL leads to fewer exacerbations and unscheduled visits [26]. In the present study, patients in the mobile telephone group had better FEV1, PEFR and QoL compared to patients in the control group and their own baseline data.

Good control of asthma is based on the adherence to treatment guidelines (GINA) for daily management. In addition, adequate medication (controller) is essential for lung function improvement and asthma control. In Japan, medication regimen below the severity level leading to poor control of asthma has been noted in $30-48 \%$ of persistent asthmatics [27]. The poor awareness of individual asthma control level and a lack of good communication with therapists leads to difficulty in adhering to the treatment guidelines for asthma control [28]. The mobile telephone-based self-care system provides a feasible and acceptable method for self-monitoring of asthma control. This new technology handles complex calculation programmes and algorithms easily, and offers immediate response to the corresponding level of asthma control as an efficient way of communication. In addition, our system can be used as a real-time telemedicine tool to supplement outpatient monitoring [17, 29-34]. The Robert Wood Johnson Foundation [35] has noted an increased use of internet-based devices, cell phones, and personal digital assistants (PDAs) creating opportunities for both patients and providers to benefit from access to e-Health applications. All of these advantages can be amplified in the treatment of asthmatic subjects.

Recently, cell phone-based monitoring systems have been considered to have the potential to support guided selfmanagement [36]. A recent study has shown that good compliance and adherence to the exercise programme for chronic obstructive pulmonary disease are additional factors that contribute to the maintenance of clinical benefits in the mobile telephone group during the self-management period [18]. This newly developed, innovative technique, the mobile telephone-based interactive self-care system, is a promising intervention to promote good communication between patients and caregivers, resulting in better adherence to asthma management. Most mobile telephones with GPRS are support commercially available. Of patients in the mobile telephone group, $49(81.7 \%)$ patients and $43(71.7 \%)$ patients were still adherent to the interactive self-care system and sent data to the website by GPRS to 3 and 6 months, respectively. We did not pre-select the study subjects and the compliance in this study was $\sim 80 \%$ in the mobile telephone group. This pilot study was not powered to detected significant differences between groups in adherence nor designed to assess the accuracy of the data recorded in the system. Although current data on subject acceptance of electronic data capture devices is limited, this study suggests the feasibility and potential value of this mobile telephone-based interactive self-care system.

The good adherence in the cell phone group can also be attributed to the user-friendly software. Since the software is compatible with most commercial mobile telephone and data are transmitted via GPRS, the monthly cost for each patient to use such a service in Taiwan is less than USD 3.00. It is simple, reliable, easy to use, and time- and cost-efficient. The asthmatic patients with frequent outdoor activities or travel benefit from using the system, as they have greater environmental exposure to allergens.

This study has several limitations. First, this study has a relatively small sample size, which may not be able to demonstrate all possible differences among the study groups. Secondly, it is a single-centre study, and the results may not be generalised to other settings. Thirdly, some asthma patients may find it difficult to operate this mobile telephone-based system. Patients who have hearing or visual impairment, or those who are not familiar with or not able to operate mobile telephones, are not suitable for this system. Finally, this is a pilot study designed to assess clinical improvement and feasibility of using a mobile telephone-based system to electronically capture clinical information in subjects with asthma. We randomised the patients using a written asthma diary booklet and action plan as control group since the strategy is suggested in current GINA guidelines to develop a partnership between patients and their healthcare team by working together. It may be expected to have better control, due to comprehensive input of data, and enhance the adherence of asthma management. In a recent study, $58 \%$ of subjects preferred the mobile telephone-based diary, lending support to the concept that subjects will accept and ultimately may prefer to use electronic data capture devices. Since it is not powered to detected significant differences in adherence between groups, nor designed to assess the accuracy of the data recorded in the system, it does not provide definitive answers at this moment. A comparison with a more simple evaluation closer to current clinical practice (e.g. asthma control test (ACT) questionnaire, performed periodically every 1-3 months) may be done in the future.

In summary, a mobile telephone-based interactive self-care system is a promising tool for supporting the self-management of asthma. Patients increased their awareness of asthma control, and benefited from a reduced rate of acute exacerbations and improved pulmonary function, as well as improved QoL, through early medical intervention.

\section{STATEMENT OF INTEREST}

None declared.

\section{ACKNOWLEDGEMENTS}

The authors express their gratitude to the team leader B. Hung, engineers R. Chang, J. Tseng, A. Cheng, and J. Lin (all National Center for High-Performance Computing, Hsinchu, Taiwan) for designing the software installed on the mobile telephones and maintaining the website for data storage, and their valuable suggestions for this article.

\section{REFERENCES}

1 Moorman JE, Rudd RA, Johnson CA, et al. National surveillance for asthma: United States, 1980-2004. MMWR Surveill Summ 2007; 56: $1-54$.

2 Anandan C, Nurmatov U, van Schayck OC, et al. Is the prevalence of asthma declining? Systematic review of epidemiological studies. Allergy, 65: 152-167.

3 Jan IS, Chou WH, Wang JD, et al. Prevalence of and major risk factors for adult bronchial asthma in Taipei City. J Formos Med Assoc 2004; 103: 259-263. 
4 Bender BG, Rand C. Medication non-adherence and asthma treatment cost. Curr Opin Allergy Clin Immunol 2004; 4: 191-195.

5 Bender BG, Bender SE. Patient-identified barriers to asthma treatment adherence: responses to interviews, focus groups, and questionnaires. Immunol Allergy Clin North Am 2005; 25: 107-130.

6 Heaney LG, Robinson DS. Severe asthma treatment: need for characterising patients. Lancet 2005; 365: 974-976.

7 Barnes PJ. Introduction: how can we improve asthma management? Curr Med Res Opin 2005; 21: Suppl. 4, S1-S3.

8 Barnes PJ. Achieving asthma control. Curr Med Res Opin 2005; 21 : Suppl. 4, S5-S9.

9 Yeh KW, Chen SH, Chiang LC, et al. Survey of asthma care in Taiwan: a comparison of asthma specialists and general practitioners. Ann Allergy Asthma Immunol 2006; 96: 593-599.

10 Gibson PG, Powell H, Coughlan J, et al. Self-management education and regular practitioner review for adults with asthma. Cochrane Database Syst Rev 2003; 1: CD001117.

11 Ostojic V, Cvoriscec B, Ostojic SB, et al. Improving asthma control through telemedicine: a study of short-message service. Telemed J E Health 2005; 11: 28-35.

12 Jaana M, Pare G, Sicotte C. Home telemonitoring for respiratory conditions: a systematic review. Am J Manag Care 2009; 15: 313-320.

13 Jan RL, Wang JY, Huang MC, et al. An internet-based interactive telemonitoring system for improving childhood asthma outcomes in Taiwan. Telemed J E Health 2007; 13: 257-268.

14 Rasmussen LM, Phanareth $\mathrm{K}$, Nolte $\mathrm{H}$, et al. Internet-based monitoring of asthma: a long-term, randomized clinical study of 300 asthmatic subjects. J Allergy Clin Immunol 2005; 115: 1137-1142.

15 Willems DC, Joore MA, Hendriks JJ, et al. Process evaluation of a nurse-led telemonitoring programme for patients with asthma. J Telemed Telecare 2007; 13: 310-317.

16 Chan DS, Callahan CW, Hatch-Pigott VB, et al. Internet-based home monitoring and education of children with asthma is comparable to ideal office-based care: results of a 1-year asthma in-home monitoring trial. Pediatrics 2007; 119: 569-578.

17 Guendelman S, Meade K, Benson M, et al. Improving asthma outcomes and self-management behaviors of inner-city children: a randomized trial of the Health Buddy interactive device and an asthma diary. Arch Pediatr Adolesc Med 2002; 156: 114-120.

18 Liu W-T, Wang C-H, Lin H-C, et al. Efficacy of a cell phone-based exercise programme for COPD. Eur Respir J 2008; 32: 651-659.

19 Standards for the diagnosis and care of patients with chronic obstructive pulmonary disease (COPD) and asthma. This official statement of the American Thoracic Society was adopted by the ATS Board of Directors, November 1986. Am Rev Respir Dis 1987; 136: 225-244.

20 Global Initiative for Asthma. Global Strategy for Asthma Management and Prevention. Geneva, GINA, 2006.

21 Buchner DA, Butt LT, De Stefano A, et al. Effects of an asthma management program on the asthmatic member: patient-centered results of a 2-year study in a managed care organization. Am J Manag Care 1998; 4: 1288-1297.

22 Giraud V, Roche N. Misuse of corticosteroid metered-dose inhaler is associated with decreased asthma stability. Eur Respir J 2002; 19: 246-251.

23 Silva GE, Sherrill DL, Guerra S, et al. Asthma as a risk factor for COPD in a longitudinal study. Chest 2004; 126: 59-65.

24 Selroos $\mathrm{O}$, Lofroos $\mathrm{AB}$, Pietinalho $\mathrm{A}$, et al. Asthma control and steroid doses 5 years after early or delayed introduction of inhaled corticosteroids in asthma: a real-life study. Respir Med 2004; 98: 254-262.

25 Orr LC, Fowler SJ, Lipworth BJ. Relationship between changes in quality of life and measures of lung function and bronchial hyperresponsiveness during high-dose inhaled corticosteroid treatment in uncontrolled asthma. Am J Respir Med 2003; 2: 433-438.

26 Magid DJ, Houry D, Ellis J, et al. Health-related quality of life predicts emergency department utilization for patients with asthma. Ann Emerg Med 2004; 43: 551-557.

27 Tomita K, Hanaki K, Hasegawa Y, et al. Underrecognition of the severity of asthma and undertreatment of asthma in a rural area of Japan. J Asthma 2005; 42: 689-696.

28 Moffat M, Cleland J, van der Molen $\mathrm{T}$, et al. Poor communication may impair optimal asthma care: a qualitative study. Fam Pract 2007; 24: 65-70.

29 Finkelstein J, Hripcsak G, Cabrera MR. Patients' acceptance of Internet-based home asthma telemonitoring. Proc AMIA Symp 1998; 336-340.

30 Finkelstein J, Cabrera MR, Hripcsak G. Internet-based home asthma telemonitoring: can patients handle the technology? Chest 2000; 117: 148-155.

31 Reddel HK, Ware SI, Salome CM, et al. Pitfalls in processing home electronic spirometric data in asthma. Eur Respir J 1998; 12: 853-858.

32 Homer C, Susskind O, Alpert HR, et al. An evaluation of an innovative multimedia educational software program for asthma management: report of a randomized, controlled trial. Pediatrics 2000; 106: 210-215.

33 Romano MJ, Hernandez J, Gaylor A, et al. Improvement in asthma symptoms and quality of life in pediatric patients through specialty care delivered via telemedicine. Telemed J E Health 2001; 7: 281-286.

34 Anhoj J, Moldrup C. Feasibility of collecting diary data from asthma patients through mobile phones and SMS (short message service): response rate analysis and focus group evaluation from a pilot study. J Med Internet Res 2004; 6: e42.

35 Health e-Technologies Initiative. www.hetinitiative.org Date last updated: April 2009.

36 Hung SH, Tseng HC, Tsai WH, et al. Care for asthma via mobile phone (CAMP). Stud Health Technol Inform 2007; 126: 137-143. 